\title{
Fatigue-Strength Prediction of Microelectronics Solder Joints Under Thermal Cyclic Loading
}

\author{
Qiang Yu and Masaki Shiratori
}

\begin{abstract}
The stress-strain analyses for the solder joints in a thin single outline package (TSOP), a ball grid array (BGA) assembly, and a leadless ceramic chip carrier (LCCC) are carried out to investigate the plastic-creep behavior, and stress relaxation bchavior due to the temperature cycling or isothermal cyclic loading. The temperature dependence of plastic behavior (yield stress) and creep behavior (creep properties) are taken into consideration in all numerical analyses. The results of tinite element analysis (FEA) show that in an accelerated temperature cycling test, long high-temperature and low-temperature dwell times do not contribute to the increase of the cyclic inelastic equivalent strain range in solder joints (although the creep behavior occurring during the dwell times in an operating condition is important enough to be taken into consideration for estimating the fatigue life of solder joints). Based upon the results of the strain analyses, some efficient testing processes of temperature cycling and isothermal fatigue tests for the microelectronic solder joints are proposed, and the cycling tests are carried out. The experimental results show a good agreement with the analytic results.
\end{abstract}

Index Terms-Ball grid array, finite element analysis, leadless ceramic clip carrier, local thermal expansion coefficients, thin single outline packange.

\section{INTRODUCTION}

$\mathbf{M}$ ANY researchers have studied the strain behaviors of the stress-strain history with considering the effect of the thermal cycling conditions [15]. [16]. In order to cstimate the creep behavior of solder joint occurring during the temperature changing time [14] proposed an accurate finite element analysis (FEA) method to investigate the elasticplastic, and creep behavior in the solder joints of thin single outline package (TSOP). It was showed that it was very important that the creep behavior during the temperature loading and unloading was taken into consideration. Based upon the analytic results, they concluded that the long dwell times are not cfficient to increase the cyclic strain range for a local thermal expansion coefficients (CTE) mismatch model.

For the fatigue strength prediction [5] showed that based upon the Coffin-Manson's law the fatigue life could be evaluated by the results of nonlinear three-dimensional (3D) FEA. Reference [2] proposed a strain-energy partitioning critcrion, which is similar to the Halford-Manson strain-rangc partitioning method [6], [11] for examining the effect of

Manuscript received February 1. 1997; revised May 1, 1997.

The authors are with the Department of Mechanical Engineering atnd Malcrials Science, Yokohama National University. Hodogaya-ku, Yokohama 240, Japan (c-mail: masaki@swan.me.ynu.ik.jp; qiang@swan.me.ynu.ac.jp). Publisher liem Identifier S 1070-9886(97)06040-X. cyclic temperature range on fatigue life. It should be noticed that the proportion of the each component of the strains (elastic/plastic/creep) must correctly be determined in using each critcrion.

In this stuody, the basic behavior of the sieady-state creep rate and the stress relaxation for the eutectic $\mathrm{Sn}-\mathrm{Pb}$ solder material was studied. The stress-strain behavior in the microclectronic solder joints subjected to the temperature cycling condition and the isothermal cyclic loading was investigated. where the temperature dependence of plastic behavior and creep behavior were taken into consideration. Based upon the results of the stress-strain analyses, the more suitable thermal testing processes were proposed to evaluate thermal fatigue life instead of the usual methods. It was expected that by using the present processes of thermal fatigue test, the estimation of fatiguc strength for the solder joint can be carricd out more casily. Finally, a serics of fatigue tests were carried out to investigate the fatigue bchaviors of solder joints, and the results were discussed by analyzing the strain hysteresis.

\section{Mechanical Properties of Solder Material}

The eutectic Sn-Pb solder was chosen to be discussed in this study. It is well known that it is the most important to use the accurate material properties in the FEA, and the basic study for the mechanical behavior of the materials is very useful for rescarchers to understand the complicated numerical results.

Several empirical expressions have been obtained to describe the steady-state creep behavior of the eutectic $\mathrm{Sn}-\mathrm{Pb}$ solder, such as the traditional "power law," the hyperbolicsine function, and so on. In this study, a power law was used for all analyses as

$$
\dot{\varepsilon}_{c}=A \cdot \sigma^{\prime \prime} \exp (-Q / R T)
$$

The creep constants $A, n$, depend on the dominant creep mechanism, $Q$ is the relevant activation energy for creep. which is near the relevant activation encrgy for grain boundary diffusion in both $\mathrm{Pb}$ and $\mathrm{Sn}$. The constants $A, n$ and $Q / R$ used in this paper were determined by the experimental data tested by [7], i.c., $A=3.29 e+11 . n=5.66 \times 10^{-00288(T-273)}$, and $Q / R=13180.0 . \sigma$ is the Mises equivalent stress, and $T$ is the absolute temperature. The temperature dependence of the yicld strength was used as

$$
\sigma_{f}=81.47-0.1833 T
$$






Fig. 1. Maximum creep ratc of eutectic $\mathrm{Sn} \cdot \mathrm{Pb}$ solder.

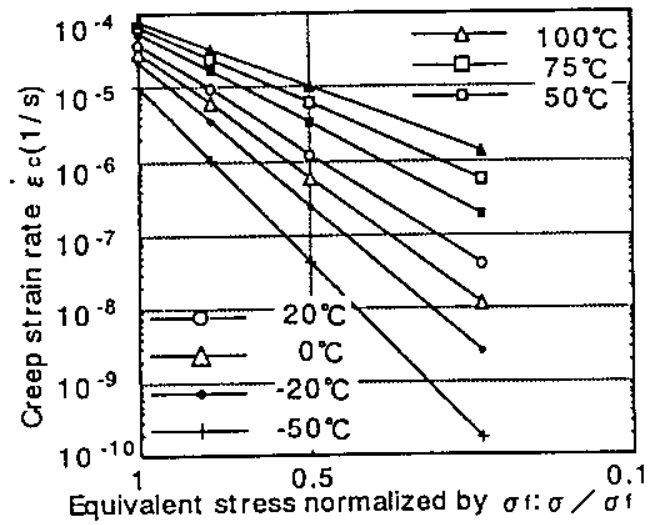

Fig. 2. Influence of stress relaxation on ereep strain rate.

\section{A. Steady-State Creep Rate and Maximum Creep Rate}

Steady-state crecp rate, $\dot{\varepsilon}_{c}$ means creep strain per unit time in response to a constant stress. According to (I), at the same temperature the steady state creep rate depends on only the stress lever. When the stress $\sigma$ reaches the yield strength $\sigma_{f}$, the steady-state creep rate $\dot{\varepsilon}_{c}$ reaches the maximum value (for the perfectly plastic model), and $\dot{\varepsilon}_{c \text { max }}$ can be expressed as

$$
\dot{\varepsilon}_{\mathrm{c} \max }=A \sigma_{f n} \operatorname{cxp}(-Q / R T) .
$$

Fig. 1 shows the maximum creep strain rate at several typical temperatures. Since the yield strength at low temperature is much greater than that at high temperature, the maximum creep strain rate at low temperature does not decrease very lowly, in the other words the maximum creep strain rates are not very different whether at high temperature or at low temperature.

\section{B. Stress Relatation}

As shown in (1), at low temperature the creep hardening exponent $\mathbf{n}$ is great, and creep constant $A \cdot \exp (Q / R)$ is small, so the creep strain rate will decrease sharply during the stress relaxation. Fig. 2 shows the changing of creep strain rate during the stress relaxation at several typical temperatures, where the initial stress values were assumed to be the yield strengths at each temperature. The axis of abscissa shows the equivalent stress normalized by the yield strengths of each temperature. It is shown that at the beginning of the stress relaxation the strain rates at low temperature are not so different from these at high temperature comparatively, but


Fig. 3. Analytic modeis used in this study.

TABLE I

Material Propiekties Used in fMA

\begin{tabular}{l|l|l|l|l}
\hline \multirow{4}{*}{ Model } & Component & $\begin{array}{l}\text { Young's } \\
\text { modulus(GPa) }\end{array}$ & $\begin{array}{l}\text { Poisson's } \\
\text { Ratio }\end{array}$ & $\begin{array}{l}\text { CTE } \\
\mathrm{ppm} / \mathrm{K}\end{array}$ \\
\hline \multirow{4}{*}{ TSOP } & Package & 10 & 0.2 & 18 \\
\cline { 2 - 5 } & Lead & 147 & 0.3 & 3.4 \\
\cline { 2 - 5 } & Substratc & 10 & 0.2 & 13 \\
\hline \multirow{4}{*}{ BGA } & Encap. & 16 & 0.25 & 15 \\
\cline { 2 - 5 } & Chip & 130 & 0.28 & 2.6 \\
\cline { 2 - 5 } & Substratc & 19 & 0.2 & 15 \\
\cline { 2 - 5 } & PCB & 18 & 0.19 & 16 \\
\hline \multirow{4}{*}{ LCCC } & Resistor & 255 & 0.3 & 6 \\
\cline { 2 - 5 } & PCB & 11 & 0.28 & 15 \\
\hline \multirow{7}{*}{} & Solder & 20 & 0.39 & 25 \\
\hline
\end{tabular}

with the advance of stress relaxation, the strain rates at low temperature decreases sharply and becomes very much lower than that at high temperature. Therefore, it can be assumed that creep deformation occurs only in the beginning of the stress relaxation period, and too long dwell time for the low temperature is not effective and not economical to increase the cyclic strain range. The detailed discussion of the effects of dwell time will be given later.

\section{MODEL OF FEM ANALYSIS}

In this study, the stress-strain analyses for a TSOP, a BGA assembly and a LCCC resistor were discussed by using FEA. The models are shown in Fig. 3. In order to facilitate the numerical computations, two-dimensional (2-D) models were used for the FEA's.

The material properties used in the FEA are shown in Table I. All of the materials were assumed to behave elastically 




(a)



(b)

Fig. 4. Temperature histories.

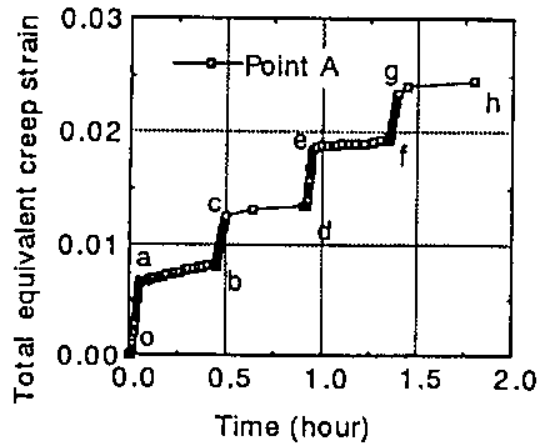

Fig. 5. Total equivalent creep strain history of TSOP (case 1).

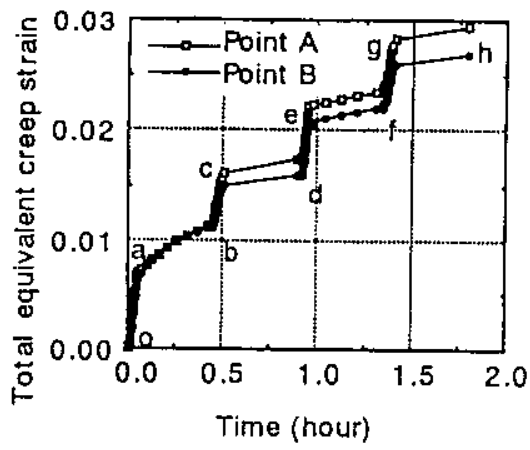

Fig. 6. Total equivalent erecp strain history of BGA (case 1).

except the solder, which was treated as a visco-plastic material. The nonlinear properties of solder were assumed to follow (1) and (2). In all analyses conducted in this study the Young's modulus and Poisson's ratio of solder were assumed to be constant. The FEA's were carried out with the general-purpose commercial FEM cord MARC and ABAQUS. Fig. 4(a) and (b) shows the temperature histories used in this study. The case 1 is an accelerated test condition, which consists of 3 min linear temperature loading/unloading ramps and $24 \mathrm{~min}$ high/low temperature dwell periods, and the temperature range is from -40 to $125^{\circ} \mathrm{C}$. The case 2 is an operating condition, which consists of $5 \mathrm{~min}$ linear temperature loading/unloading ramps and $4 \mathrm{~h}$ high/low temperature dwell periods, and the temperature range is from 20 to $65^{\circ} \mathrm{C}$.

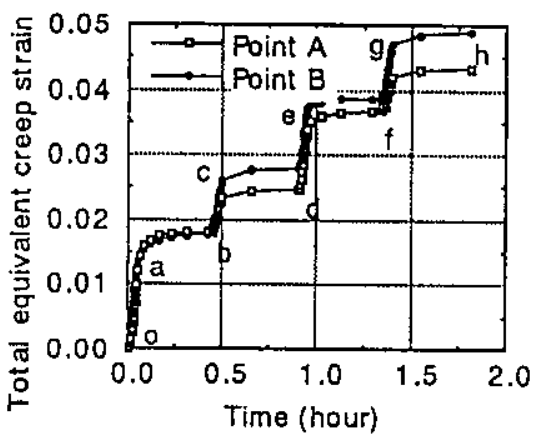

Fig. 7. Total equivialent creep strain history of LCCC (case 1).

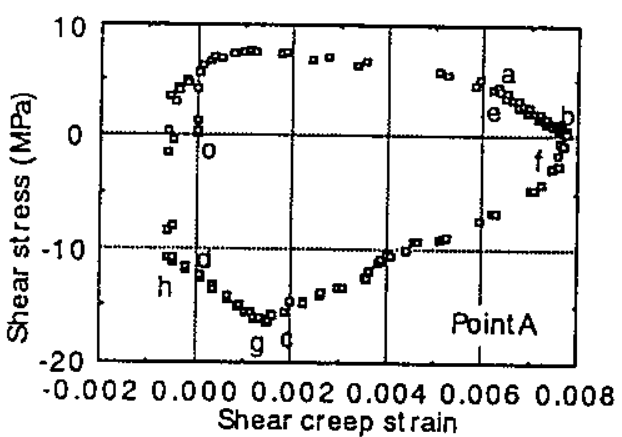

(a)

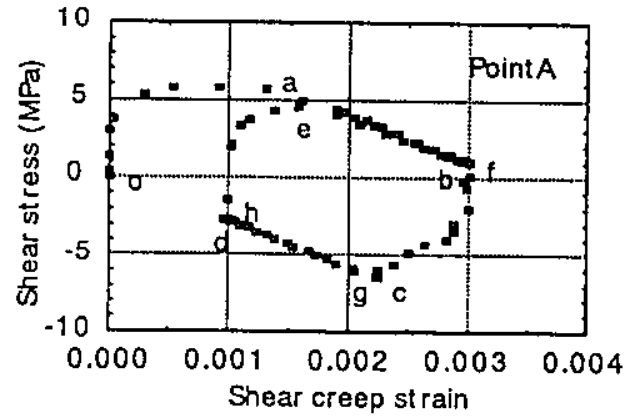

(b)

Fig. 8. Hysteresis loop of shear stress and shear creep strain in BGA (Point A).

\section{Results of Finite Element Analyses}

In a previous report, the authors have shown that it is very important to take into consideration of the creep behavior during the temperature loading and unloading, because over $50-80 \%$ of total strain range arises during temperature changing ramp [14]. In this report, all of the analyses were carried out with taking the creep behavior into account at all times (including the temperature changing and temperature dwell periods).

\section{A. Basic Stress-Strain Behavior}

Figs. 5-7 show the history plots of total equivalent creepstrain at the points $A$ and $B$ shown in Fig. 3 for the TSOP model, the BGA model and LCCC model, respectively, where the temperature cycling condition was case 1 . The symbol marks $\mathbf{0}, \mathbf{a}, \mathbf{b}, \mathbf{c}, \mathrm{d}, \mathbf{e}, \mathbf{f}, \mathbf{g}, \mathbf{h}$ in the strain histories plots correspond to the points of the temperature cycles shown in Fig. 4(a) and (b). It was found that for the BGA model, the 




(a)



(b)



(c)

Fig. 9. Total equation creep strain ranges arising during every section of temperature history (case 1).

creep strain concentrate in the corners of each ball, but the maximum creep strain arose at the point $A$ in the ball under the edge of silicon chip (the third ball from the center), not in the edge ball (the fourth ball from the center). For the LCCC model, although the maximum creep strain arose in the corner point $B$, the stress-strain behavior at the edge point $A$ was also discussed in this study because a fatigue crack always arises from A.

Fig. 8(a) and (b) shows the hysteresis plots of shear stress and shear creep strain in BGA model. It was found that in the case 2 (operating condition), the strain range arising during the temperature dwell time was almost equal to that arising in the temperature changing time, but in the case 1 (accelerated test condition), the strain range arising during the temperature dwell periods was very small and occurred in the beginning of the periods. Fig. 9(a)-(c) shows the inclastic equivalent strain ranges arising during each period of the temperature history of case 1 (accelerated test condition). The strain ranges arising in the temperature dwell are very small not only in the BGA model, but also in the LCCC model and the TSOP model. Fig. 10 shows the results of the temperature history of case 2 (operating condition). It was found that the strain ranges arising during the dwell time were almost equal to these arising during the temperature changing time in all kinds of solder joints. The results of Figs. 9 and 10 mean that the strain ranges arising in the dwell time of an operating condition (the low temperature is higher than $20^{\circ} \mathrm{C}$ ) are very important to be taken into consideration to evaluate the fatigue strength of solder joint, but the strain ranges arising during the dwell time of an accelerated test (the low temperature is lower than $-40^{\circ} \mathrm{C}$ ) are not so important. The detail of the effect of the dwell time on the total cyclic strain range in the accelerated test will be discussed in the neat section.

\section{B. Influences of Testing Conditions}

It has been pointed out that the total inelastic equivalent strain range of solder joint in a TSOP was not affected by the testing conditions of the temperature dwell time and temperature changing rate. In this study, in order to design an efficient accelerated thermal cycling test for all kinds of microelectronic solder joints, the effect of temperature dwell time on the creep behavior of BGA solder joints and LCCC solder joints were necessary to be make clear, because the solder joints in the TSOP, the BGA and LCCC are typical of all kinds of the solder joints. For setting the isothermal fatigue test, the effect of the total strain rate on the strain histories was discussed. Based upon the results of these analyses, the efficient fatigue testing conditions were discussed in the next section.

\section{Influence of Dwell Time}

Fig. 11 shows the effect of dwell time to the total inelastic equivalent strain range for the TSOP model, BGA model, and LCCC model in the accelerated test condition. These analyses are carried out with the dwell times of $6 \mathrm{~min}, 10 \mathrm{~min}, 24 \mathrm{~min}$, and $50 \mathrm{~min}$, respectively. It could be seen that the strain ranges were affected by the dwell time very little, when the dwell time 


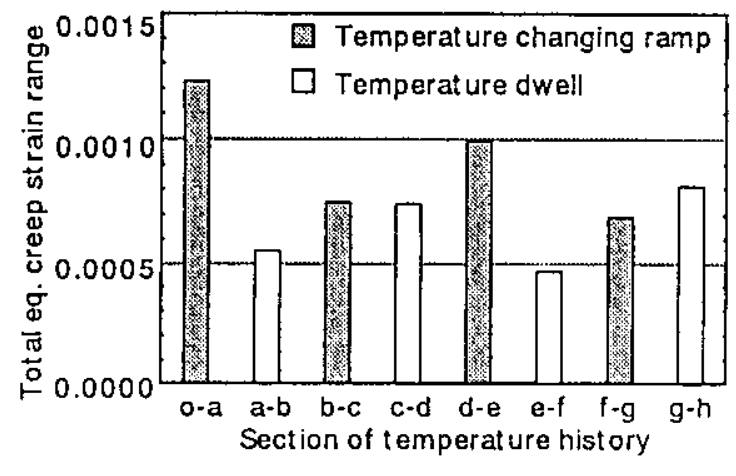

(a)

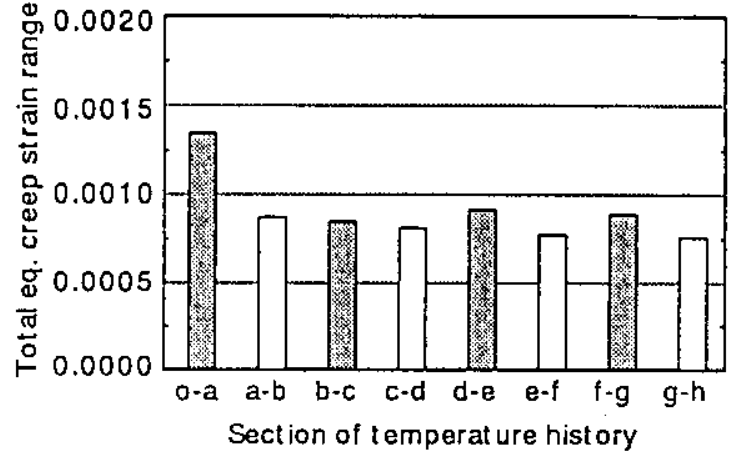

(b)

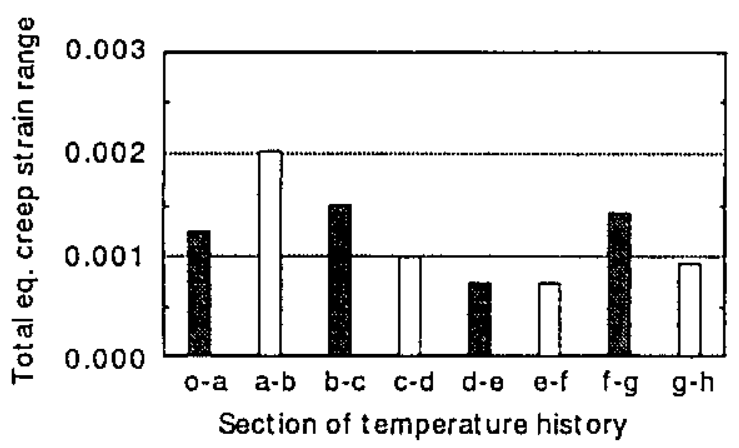

(c)

Fig. 10. Total equation creep strain ranges arising during every section of temperature history (case 2).

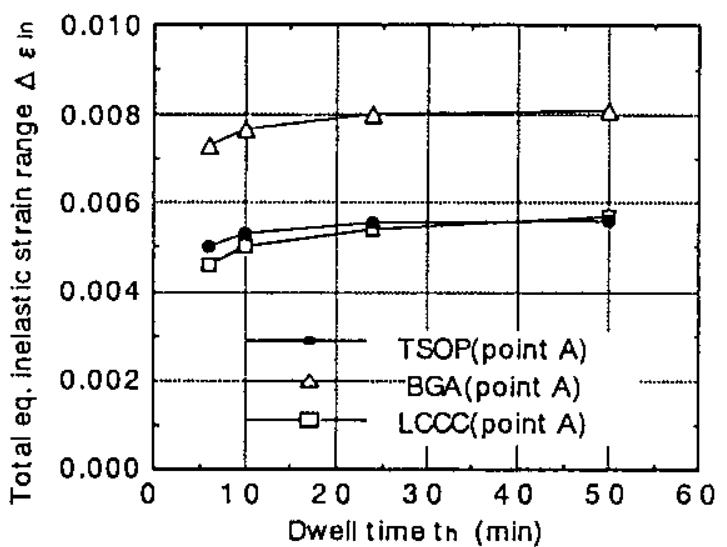

Fig. 11. Effect of dwell time $t_{k}$ on total equation inelastic range $\Delta \varepsilon_{i n}$.

are longer than 24 min. This is because creep strain rate of the solder slows down sharply due to the stress relaxation at low temperature, as shown in Fig. 2, so the creep strain range in low temperature dwell time can not increase at all. Since the total strain ranges arising during both temperature changing ramps were almost even, as shown in Fig. 9(a)-(c), the creep strain ranges arising during high temperature-dwell time were limited by these arose during low temperature-dwell time. As a result, the dwell time is not effective for low-temperature dwell, as well as for high temperature dwell. This conclusion is true for the solder joints in all kinds of the assemblies.

\section{Influcnce of Total Strain Rate}

Fig. 12 shows the effect of the time $t_{c}$ of temperature changing ramp to the total inelastic equivalent strain ranges for the TSOP, the BGA, and the LCCC models, where all analyses for the same model were carried out with the same dwell time. The axis of abscissa shows the cyclic inelastic equivalent strain range normalized by the results given by the condition of $t_{c}=0$. It is found that the strain range increased as the temperature changing time became very short in the $\mathrm{BGA}$ and LCCC models, but the strain range little changed in the TSOP. This is because that great stress concentration occurred near the point $A$ in the BAG and LCCC models, but no so remarkable stress concentration appeared in the TSOP model.

\section{Design of Fatigue Strength Test}

\section{A. Accelerated Thermal Cycling Test}

Based upon the above analytic results, the more suitable testing processes can be designed to evaluate thermal fatigue life instead of the usual methods. For example, for the case of the temperature cycling test, since Fig. 11 shows that the strain range of a steady-state cycle is not affected by the dwell time greatly, the dwell time $t_{h}$ shown in Fig. 4(a) and (b) can be set shortly for both high and low temperature, and to consider the time to uniform temperature distribution due to heat transfer, th of 8-10 $\mathrm{min}$ is long enough for the dwell time. Therefore, to add two 3-min temperature changing ramps, the shortest cycling time is $22 \mathrm{~min}$. As a result, the time to failure of the cyclic test of $10 \mathrm{~min}$ dwell time decreases to under $50 \%$ of that of 30 min dwell time. Fig. 13 shows an accelerated thermal cycling test proposed in this study. 


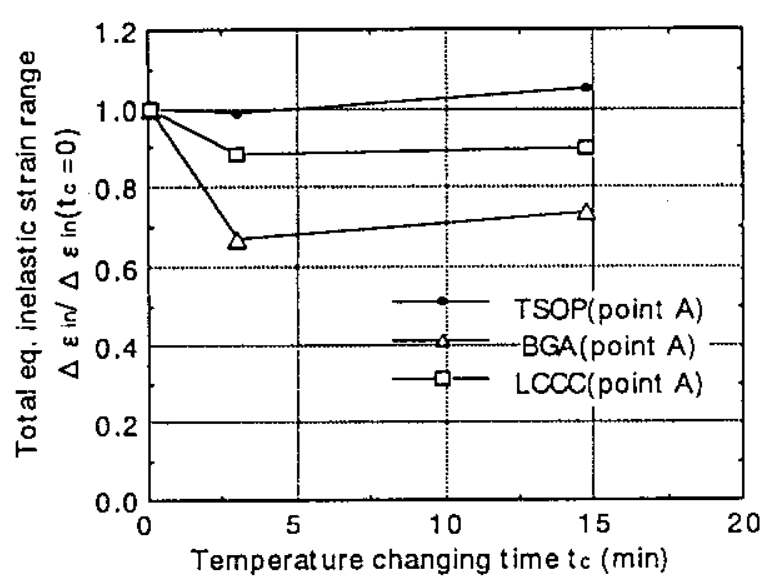

Fig. 12. Effect of temperature changing time $t_{c}$ on total equation inelastic range $\Delta \varepsilon_{\text {in }}$.

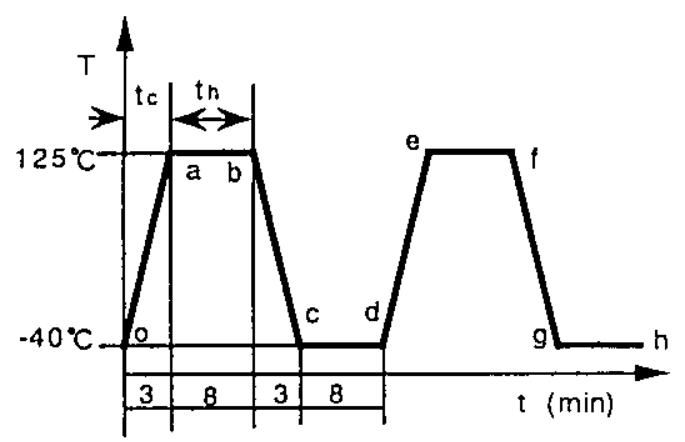

Fig. 13. Proposed condition of accelerated thermal cycling test.

\section{B. Isothermal Fatigue Test}

Some isothermal fatigue testing processes have been used to play a role of accelerated test method for the thermal cycling. In the isothermal fatigue test, the total strain rate is usually controlled as from $1.0 \mathrm{E}-1 / \mathrm{s}$ to $1.0 \mathrm{E}-5 / \mathrm{s}$. Fig. 14 shows the shear test equipment used in this study. The shear displacement was generated by a step motor. The maximum shear displacement range is $\pm 0.5 \mathrm{~mm}$, the position resolution is smaller than $0.5 \mu \mathrm{m}$, and the shear displacement rate can be conducted from $0.01 \mu \mathrm{m} / \mathrm{s}$ to $100.0 \mu \mathrm{m} / \mathrm{s}$. The leaded SMA was chosen as the specimen of isothermal fatigue test in this study, because the total inelastic equivalent strain range is hardly affected by the total strain rate, as shown in Fig. 12, and the fatigue cracks in solder joints can directly be detected by a microscope.

According to (2), the relation between the total strain rate caused by the external loading and the proportion of the strain components (plastic strain and creep strain) can be given as Fig. 15. It means that when the total strain rate is set in the areal of only creep, there not is plastic strain arising in the solder joints. On the other hand, when the strain rate is set in the area of only plastic, the plastic strain accounts for over $95 \%$ of the total inelastic strain. Because the researchers can set the external loading to control the strain rate arising in the solder joint easily and steadily by the mechanical method, the fatigue strength of solder joints can be investigated with higher degree of accuracy than by temperature cycling test. Therefore,

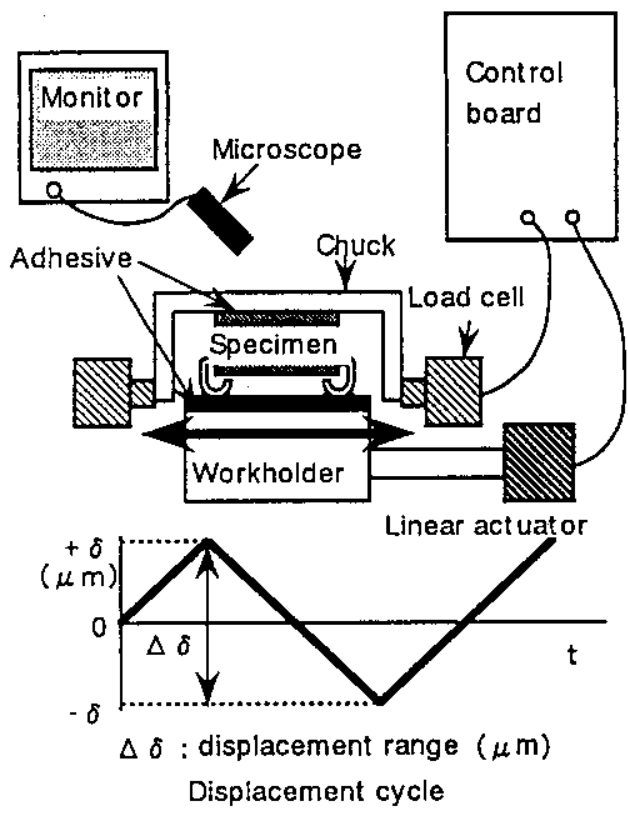

Fig. 14. Isothermal fatigue shear testing equipment.

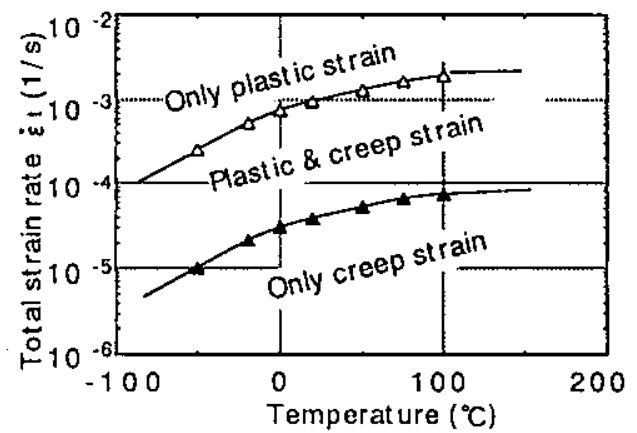

Fig. 15. Relation of total strain rate and proportion of strain components.

the testing results given by the mechanical tests can be used to make clear the fracture mechanism of solder joints due to cyclic creep strain and cyclic plastic strain, respectively.

\section{Fatigue EXPERIMENT AND RESULTS}

Based upon the analytic results, a series of fatigue test were carried out to investigate the fatigue behavior of the leaded solder joints shown in Figs. 3. At first, the thermal cycling tests were carricd out. The initial of crack was checked by a microscope, and the failure of solder joint was defined by the cycles of the crack nucleation and early growth, or when the crack reaches $0.2 \mathrm{~mm}$ length (about the width of lead).

In order to verify the relation between the cycles to failure and the dwell time, the temperature cycling testes with dwell time of 8,15 , and $25 \mathrm{~min}$ were carried out, where the tcmperature changing range was from $-30^{\circ} \mathrm{C}$ to $150^{\circ} \mathrm{C}$ and the temperature changing time was $3.5 \mathrm{~min}$ for every testing condition. The results are shown in Fig. 16. The results show that the cycles to failure of the testes with 25 min dwell time is smaller than that with $8 \mathrm{~min}$ dwell time (decreases to about $85 \%$ ), but the total testing time of the tests with $25 \mathrm{~min}$ dwell time is over twice. It has been shown that the cyclic strain 


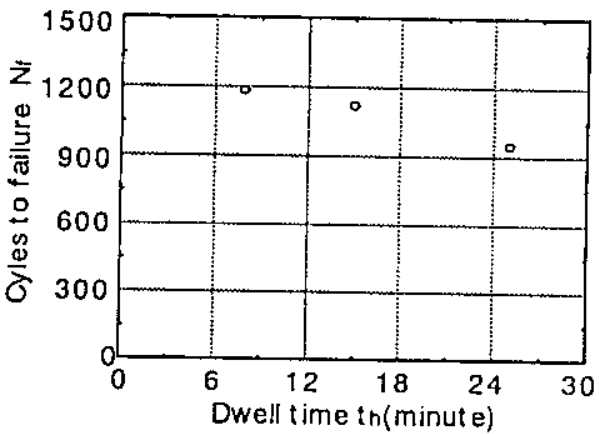

Fig. 16. Influence of dwell time $t_{h}$ on cycles to failure.

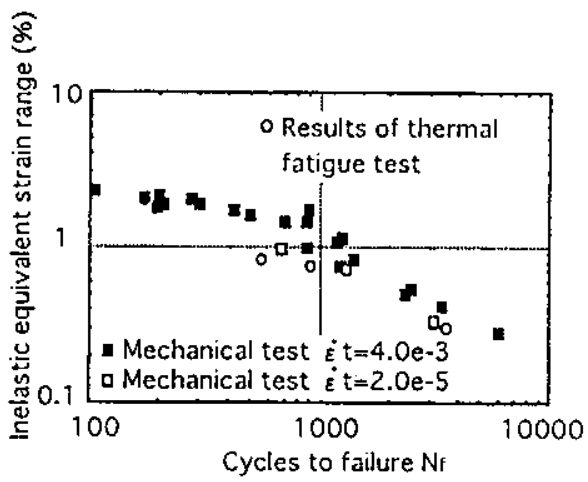

Fig. 17. Results of thermal and mechanical fatigue tests.

range arising in the solder joints was not affected by the dwell time greally, and the experimental results shown in Fig. 15 verify that their conclusion is true. Therefore, it can be said that the temperature cyclic test with short dwell time is economical.

Based upon the above experimental results, temperature cycling test with temperature range of -20 to $150^{\circ} \mathrm{C},-35$ to $150^{\circ} \mathrm{C}$, and -50 to $150^{\circ} \mathrm{C}$ were conduced for two types of leaded solder joints, gull-wing type and J-bend type. The results are shown in Fig. 17. In the same figure, the results of isothermal fatigue tests are shown together. The conditions of mechanical fatigue tests were (1) the package and the PCB (shown in Fig. 3) were fixed in $y$-direction, (2) the PCB was fixed in $x$ direction and the package was loaded by cyclic lixed displacement in $x$-direction. According to Fig. 14, the total strain rate $\varepsilon_{t}$ arising in the solder joint wats set as $4.0 \mathrm{e}-3 / \mathrm{s}$ and $2.0 \mathrm{e}$ to $5 / \mathrm{s}$, where only plastic strain component and only creep component arose, respectively. The environmental temperature was $20^{\circ} \mathrm{C}$. Every point shown in Fig. 17 expresses the average result of 40 picces of solder joint. It is shown that the results of temperature cyclic tests and mechanical cyclic tests followed the power low relation, and the results of mechanical test in low strain rate agreed with those of temperature cyclic tests, where the average strain rates were about $2.0 e-5-4.5 e-5(1 / \mathrm{s})$, and the grealer part of total inclastic equivalent strain range was creep strain.

\section{CONCLUSION}

In order to study the get a cyclic stress-strain hysteresis in microelectronic solder joints during a temperature cyclic test. a TSOP, a BGA, and a LCCC were modeled for FEA.
TABLE II

Evaluation ol: the Chlep fatigue Life of Solder Joint in BGa and lCCC

\begin{tabular}{l|c|c}
\hline & BGA & LCCC resistor \\
\hline $\begin{array}{l}\text { Acceleratcd test } \\
\text { condition(casc 1) }\end{array}$ & 1832 & 953 \\
\hline $\begin{array}{l}\text { Opcrating } \\
\text { condition(case 2) }\end{array}$ & 10532 & 9876 \\
\hline $\begin{array}{l}\text { Accclerated rate } \\
\text { Casc1/Casc2 }\end{array}$ & 5.75 & 10.36 \\
\hline
\end{tabular}

The analytic results show that for a temperature cyclic test, long high-temperature and low-temperature dwell times do not contribute to the cyclic strain range in solder joint so much. Based upon the results of the strain analyses, some efficient testing processes of temperature cycling and mechanical fatigue experiments for the microelectronics solder joint were proposed, and the cycling tests were carried out. The experimental results show a good agreement with the analytic results. The proposed experimental processes can save over $50 \%$ testing time than an usual methods.

By using the fatigue strength results given by the leaded SMA shown in Fig. 16. the fatigue life of the solder joints in the BGA and the LCCC were evaluated, and the results are shown in Table II. From the tcrm of case2/casel, the accelerated rate of the accelerated thermal cycling test can be given.

\section{REFERENCES}

[I] E. P. Busso. M. Kitano, and T. Kumazawa, "Modeling complex inclastic deformation processes in iC packiges" solder joints," ASMEJ, Electron. Packas.. vol. 116. pp. (3-15. 1994.

[2] A. Dasgupta. C. Oyan. D. Barker, and M. Pecht, "Solder creeptatigue analysis by an energy-partitioning approach," ASMEJ. Electron. Packag. vol. 114, pp. 152-160, 1992.

[3] W. Engelmaier. "Functional cycles and surface mounting attachment relability." ISHM Tedmical Monogragh Series 6984-002, ISHM, Silver Spring. MD, pp. 87-114. 1984.

[4] J. H. Lats and D. W. Rice. "Solder joint fatigue in surface mount technology: State of the art," Solid State Feclusol, pp. 91-140. Oct. 1985.

|5| J. H. Latu. D. W. Rice, and S. Erasmes. "Thermal finigue bife of 256 . pito. 0.t mam pitch plastic yuad that pakt $(\varphi f p)$ solder joim," ASME Adt: Electron. Packag., 1992.

[6] S. S. Millson. G. R. Halford. and M. H. Hirschberg. "Creep-fitigue analysis by strain-range partitioning." in Proc. ASME Symp. Design Ele'sted Temp-Lnviron.. San Francisco, CA, 1971.

[7] M. Mukai, T. Kawakani, T. Endo, and K. Takahashi, "Elastic-creep behavior and fatigue tife in an IC package solder join," in Proce 4 th A.m. Mect. Comput. Mech.. JSME. 1991, no. 910-79, pp. 223-224.

[8] T.-Y. Pan, "Thermal cycling induced plastic deformation in solder joints-Part 1: Accumulated deformation in surface moum joints," ASME J. Eltectron. Packag. vol. 113. pp. 8-15. 1991.

(9) Y.-H. Paw. S. Badgley. E. Jih. and R. Govila. "Constitutive behavior and Jow cycle thermal fatigue of $97 \mathrm{Sn}-3 \mathrm{Cu}$ solder joints," ASME J. Electrom. Packag. vol. 115, pp. 147-152, 1993.

[10] N. Paydar. Y. Tong, and H. U. Akay. "A tinjte element study of fiutors affecting fatigue life of solder joints," ASME J. Electrm. Packas.. vol. 116 . pp. 265-273, 1994 .

[1i] B. I. Sandor, "Life prediction of solder joints: Engineering mechanics methods," Solder Mech.-State of the Art Assess., pp. 363-419. 1972.

[12] V. Sarihan, "Temperature dependene viscoplastic simulation of conirolled collapse solder joint under thermal cycling," ASMEJ. Electron. Packag., vol. 115. pp. 16-22, 1993. 
[13] M. Shratori, Q. Yu, and A. Nishijima, "Analysis of stress intensity factors and probabilistic fatigue life assessment for surface cracks in flip chip solder joints," ASME Adr. Ele'ctrm. Packag., pp. 487-492. 1993.

[14] M. Staratori, Q. Yu, and S. Wang, "A computational and experimental hybrid approach to creep fatigue behavior of surface-mounted sodler joints," ASME Adv. Electron. Packas., vol, 10-1, pp. 451-457, 1995.

[15] H. D. Solomon, "High and low temperature strain-life behavior of a $\mathrm{Pb}$ rich soider," ASME J. Electron. Packag., vol. 112, pp. 123-128, 1990.

[16] S. Vaynman, "Effect of temperature on isothermal fatigue of solders," IEEE Trans. Comp., Hybrids, Manufacl. Technol, vol. 13, 1990.

[17] S. Verma, A. Dasgupta, and D. Barker, "A numerical staudy of fatigue iife of J-Leaded solder joints using the energy partitioning approach," ASME J. Electron. Packag., vol. 115, pp. 416-423, 1993.
Qiang Yu, photograph and biography not available at the time of publication.

Masaki Shiratori, photograph and biography not available at the time of publication. 


\section{IEEE TRANSACTIONS ON}

\section{COMPONENTS, PACKAGING, AND MANUFACTURING TECHNOLOGY PART A}

A PUBLICATION OF THE IEEE COMPONENTS, PACKAGING, AND MANUFACTURING TECHNOLOGY SOCIETY

SEPTEMBER 1997

VOLUME 20

NUMBER 3

IMTAEZ

(ISSN 1070-9886)

CONTRIBUTIONS FROM THE "ITHERM ' 96 " INTERNATIONAL CONFERENCE

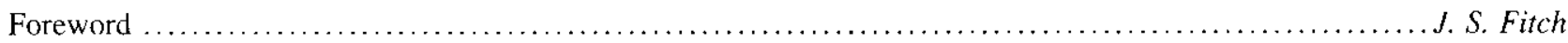

Fatigue-Strength Prediction of Microelectronics Solder Joints Under Thermal Cyclic Loading .. Q. Yu and M. Shiratori

Moisture Absorption and Desorption Predictions for Plastic Ball Grid Array Packages

J. E. Galloway and B. M. Miles

Modeling Thermally Induced Viscoplastic Deformation and Low Cycle Fatigue of CBGA Solder Joints in a Surface

Mount Package .....

B. Z. Hong and L. G. Burrell

Thermal Phenomena in Compact Electronic Enclosures: A Numerical Study

V. K. Maudgal

\section{REGULAR PAPERS}

Finite Element Analysis of PWB Warpage Due to the Solder Masking Process ...I. C. Ume, T. Martin, and J. T. Gatro Finite Element Analysis of PWB Warpage Due to Cured Solder Mask-Sensitivity Analysis. .I. C. Ume and T. Martin Coffin-Manson Fatigue Model of Underfilled Flip-Chips ................... V. Gektin, A. Bar-Cohen, and J. Ames A Study on Thermal-Stress-Reliability of Si-Based PLC Substrate ............... I. Kitazawa, S. Mino, and Y. Hibino A High Heat Flux IGBT Micro Exchanger Setup....... L. Meysenc, L. Saludjian, A. Bricard, S. Raël, and C. Schaeffer Adhesion Strength and Microstructural Evaluation in Electroless Ni-P Metallized AlN Substrate .....

OPEN FORUM

Editorial M. G. Pecht

\section{ANNOUNCEMENTS}

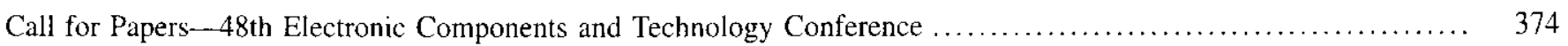

Call for Papers-14th IEEE Semiconductor Thermal Measurement and Management Symposium ................. 375

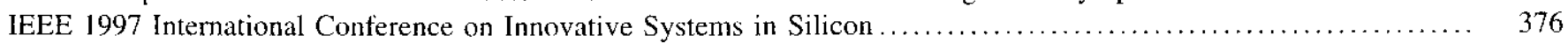

